\title{
Identification and cloning of immunogenic Aliivibrio salmonicida Pal-like protein present in profiled outer membrane and secreted subproteome
}

\author{
Christian Karlsen $^{1}$, Sigrun Espelid ${ }^{1,2,+}$, Nils-Peder Willassen ${ }^{1,2}$, Steinar M. Paulsen ${ }^{3, *}$ \\ ${ }^{1}$ Department of Molecular Biotechnology, Institute of Medical Biology, Faculty of Medicine, University of Tromsø, 9037 \\ Tromsø, Norway \\ ${ }^{2}$ The Norwegian Structural Biology Centre, University of Tromsø, 9037 Tromsø, Norway \\ ${ }^{3}$ Institute of Medical Biology, University of Tromsø, 9037 Tromsø, Norway
}

\begin{abstract}
Aliivibrio salmonicida is the aetiological agent of cold water vibriosis affecting farmed fish species, a disease that today is fully controlled by vaccination. However, the molecular mechanisms behind the successful vaccine are largely unknown. In order to gain insight into the possible mechanisms of $A$. salmonicida vaccines, we report here the profiles of both the outer membrane and secreted subproteomes of A. salmonicida LFI315. The 2 subproteomes were resolved by 2-dimensional electrophoresis that identified a total of 82 protein entries. Monoclonal antibodies specific to an unidentified protein antigen were utilized in the immunoproteomic analysis of both outer membrane proteins and extracellular proteins. The immunogenic protein was located in both subproteomes and identified as a $20 \mathrm{kDa}$ peptidoglycan-associated lipoprotein (Pal). The identity of the antigen was verified by heterologous expression of the cloned A. salmonicida pal gene (VSAL_I1899). It is likely that the immunogenic Pal-like protein is among the constituents that act as a protective antigen in the successful vaccine used today. In view of this, it may be considered a potentially useful component in future vaccine development and pathogenicity studies.
\end{abstract}

KEY WORDS: Aliivibrio salmonicida $\cdot$ Outer membrane protein $\cdot$ OMP · Extracellular product $\cdot$ ECP Immunogenic

Resale or republication not permitted without written consent of the publisher

\section{INTRODUCTION}

Aliivibrio salmonicida (formerly Vibrio salmonicida Urbanczyk et al. 2007) is the aetiological agent of cold water vibriosis in sea-farmed Atlantic salmon Salmo salar, rainbow trout Oncorhynchus mykiss and Atlantic cod Gadus morhua (Egidius et al. 1981, 1986, Jørgensen et al. 1989). All farmed Atlantic salmon are today vaccinated with oil-adjuvanted multicomponent vaccines, and no outbreaks were detected in Norwegian farms in 2009 (Bornø et al. 2010). However, the detailed molecular mechanisms underlying the protective nature of the vaccine are unknown. It may result from the $A$. salmonicida constituent, crossprotection from one of the other vaccine components, the oil adjuvant, or a combination of 2 or more of these factors. Disease outbreaks are associated with low temperatures $\left(<10^{\circ} \mathrm{C}\right)$, but no pathogenicity mechanisms have been verified in A. salmonicida. Also, little is known about the protective immune responses against the pathogen in Atlantic salmon.

Genes and systems that might play central roles in the virulence of Aliivibrio salmonicida include several protein secretion systems ( 3 T1SS, 1 T2SS, 2 T6SS and 1 Flp-type pilus system; Hjerde et al. 2008) and 2 putative haemolysins. Intriguingly, in contrast to the majority of pathogenic bacteria, $A$. salmonicida has not been shown to induce any extracellular protease activity or cytotoxicity in cell models although numerous experiments have been performed (Hjelmeland et al. 1988, 
present study data not presented). Other candidate genes and systems are, for example, iron acquisition systems linked to virulence mechanisms in several vibrios (Stork et al. 2004). Iron acquisition in A. salmonicida is proposed to constitute a temperature-sensitive virulence factor, as siderophore production is only detected at $\leq 10^{\circ} \mathrm{C}$. An alternative non-siderophorebased iron assimilation system was also detected. In addition, 3 high-molecular-weight outer membrane proteins (OMPs) were found expressed under ironrestricted growth at 6 and $10^{\circ} \mathrm{C}$, but suppressed at $15^{\circ} \mathrm{C}$ (Colquhoun \& Sørum 2001). Genomic analysis of A. salmonicida revealed 3 tonB systems and 1 heme uptake system that may be involved in iron acquisition (Hjerde et al. 2008). The $76 \mathrm{kDa}$ outer membrane protein VS-P2 that is produced only in unshaken cultures at $10^{\circ} \mathrm{C}$ or less does not have the ability to stimulate a specific humoral response (Colquhoun et al. 2002). An outer membrane proteomic study demonstrated that flagellin production and motility were regulated in response to salt concentration, as seawater-like conditions elevate flagellin production and motility compared to physiological-like salt conditions (Karlsen et al. 2008). Furthermore, fish skin mucus has been shown to stimulate expression of flagellar proteins and proteins involved in oxidative stress responses (Uttakleic Raeder et al. 2007). Flagella and motility in several species within the Vibrio and Aliivibrio groups are linked to host colonization and virulence (Richardson 1991, Graf et al. 1994, Ormonde et al. 2000, Lee et al. 2004). It has also been hypothesized that the production of hydrogen peroxide may act as a possible virulence factor in A. salmonicida (Fidopiastis et al. 1999).

Similar to other rough-type Gram-negative bacteria, Aliivibrio salmonicida carries a rough-type lipopolysaccharide (LPS) surface structure composed of Lipid A linked to low-molecular-weight oligosaccharides (Bøgwald et al. 1991, Edebrink et al. 1996). The immunogenicity of A. salmonicida resides mainly in 2 molecules associated with the outer membrane fraction of the bacterium (Espelid et al. 1987, 1988). The dominant immuno-component is the surface layer complex VS-P1, secreted from living cells into growth medium, fish tissue, or fish serum (Hjelmeland et al. 1988). Thirteen out of 17 monoclonal antibodies (MAbs) against A. salmonicida LFI83001 demonstrated specificity for VS-P1, comprising both the antigenic low molecular LPS molecules and a $40 \mathrm{kDa}$ OMP. The 4 remaining MAbs showed specificity to a membrane-associated $24 \mathrm{kDa}$ protein (Espelid 1986, Espelid et al. 1987, 1988, Bøgwald et al. 1990, 1991). The molecule was later detected in the culture supernatant when grown in minimal media, but not in marine broth (Knudsen 1991, Stuge 1992). The importance of VS-P1 in A. salmonicida pathogenesis is well documented, and it has been hy- pothesized that, as the bacterium releases VS-P1, specific antibodies will bind to the complex and thus save the bacterium from complement-mediated killing and phagocytosis (Hjelmeland et al. 1988). The outer membrane of Gram-negative bacteria encompasses various antigenic structures that are recognized by antibodies and, therefore, initiate the protective immune response. By administrating such antigens through vaccinations, acquired immunity could be induced in the recipients, which would develop an increased protection against the disease. A variety of OMPs of pathogens have been repeatedly detected by immunoproteomics (McKevitt et al. 2005, Ying et al. 2005); among them is the peptidoglycan-associated lipoprotein $(\mathrm{Pal})$, which is also found circulating in Gram-negative sepsis. The protein is anchored in the outer membrane, where it constitutes a part of a multiprotein membrane-spanning Tol-Pal complex involved in maintaining the outer membrane integrity of Gram-negative bacteria (Godlewska et al. 2009). Pal proteins are highly conserved, and homologs to the pal sequences have been widely reported (Parsons et al. 2006). Gene clusters of Tol-Pal systems are detected in most sequenced Gram-negative bacteria, but not in Gram-positive bacteria. In order to reveal the immunogenic surface structures of $A$. salmonicida, the present study deals with proteomics in combination with liquid chromatography coupled with tandem mass spectrometry (LC-MS/MS) to identify the native and heterologously expressed locus VSAL_I1899 of A. salmonicida LFI1238.

\section{MATERIALS AND METHODS}

Bacterial strains, plasmids and culture conditions. Aliivibrio salmonicida Strain LFI315 (NOFIMA culture collection; Tromsø, Norway), originally isolated from the head kidney of an Atlantic salmon diagnosed with cold water vibriosis (Norwegian fish farm, 1996) was plated on blood agar (agar base No. 2, Oxoid CM271, $7 \%$ human whole blood, $2 \%[\mathrm{w} / \mathrm{v}] \mathrm{NaCl}$ ). A single colony was expanded overnight at $200 \mathrm{rpm}$ in $5 \mathrm{ml}$ Luria-Bertani (LB) containing $1.0 \% \mathrm{NaCl}$ at $7.5^{\circ} \mathrm{C}$. The pre-culture was diluted and further expanded in batches of $250 \mathrm{ml}$. Cultures were harvested in mid-log phase $(\mathrm{OD}=0.65)$ by centrifugation $(4000 \times g, 10 \mathrm{~min}$ at $4^{\circ} \mathrm{C}$ ). The A. salmonicida gene encoding Pal (VSAL I1899) was amplified from total DNA (Forward: 5'-AAA AAG CAG GCT TCA TGC AAC TAA ATA AAC TTC TTA AG-3' and Reverse: 5'-AGA AAG CTG GGT CTT AGT ATA CTA ATA CTG CAC GAC G-3'), cloned and heterologously expressed utilizing the Gateway system (Invitrogen). Two Escherichia coli strains, BL21 (DE3) (Invitrogen) and BL21 CodonPlus (DE3) (Stratagene), were transformed with the 
pDEST17 vector containing the A. salmonicida pal gene and induced with $1 \mathrm{mM}$ isopropyl $\beta$-D-1-thiogalactopyranoside at $20^{\circ} \mathrm{C}$ overnight. The constructs were verified by DNA sequencing.

Preparation of outer membrane and extracellular proteins. OMPs were isolated as previously described (Karlsen et al. 2008). Extracellular products (ECPs) were extracted from the culture supernatant by supplementing it with phenylmethylsulfonyl fluoride to a final concentration of $5 \mu \mathrm{M}$ before filtering it through a $0.2 \mu \mathrm{m}$ membrane (MF75, Nalgene). Proteins were precipitated on ice over night in $6 \%(\mathrm{w} / \mathrm{v})$ trichloroacetic acid (Fluka) with $0.2 \mu \mathrm{g} \mathrm{ml} \mathrm{m}^{-1}$ of $\mathrm{Na}-$ deoxycholate (Sigma). The precipitate was centrifuged $\left(6000 \times g, 1 \mathrm{~h}, 4^{\circ} \mathrm{C}\right)$ and washed 3 times with ice-cold acetone to remove traces of the trichloroacetic acid. Protein concentration was measured (Bradford 1976) before it was resolubilized in rehydration solution: $7 \mathrm{M}$ urea, 2 M thiourea, $4 \%$ (w/v) CHAPS and 10\% (v/v) glycerol with freshly made $0.2 \%(\mathrm{w} / \mathrm{v})$ dithiotreitol (DTT) and $0.5 \%$ (v/v) pharmalyte ( $\mathrm{pH} 3$ to 11 nonlinear, NL).

Separation and visualization of protein fractions. Two-dimensional PAGE was performed as previously described (Karlsen et al. 2008). Briefly, protein samples (150 mg) were passively rehydrated for $1 \mathrm{~h}$ on a nonlinear immobilized $\mathrm{pH}$ gradient strip (3.0 to 11.0 NL IPG $13 \mathrm{~cm}, \mathrm{GE}$ Healthcare). Isoelectric focusing was completed at $45 \mathrm{kVh}$, and sodium dodecyl sulfate polyacrylamide gel electrophoresis (SDS-PAGE) separation was performed with $12 \%$ acrylamide gels run in a Protean II xi 2-D cell system (Bio-Rad) with a Laemmli buffer system (Laemmli 1970). Gels applied $150 \mathrm{~V}$ and $10 \mathrm{~mA} \mathrm{gel}^{-1}$ overnight were stained with GelCode Blue Stain Reagent (Pierce Biotechnology) and imaged with Fluor-S Multilmager (Bio-Rad). Samples separated by SDS-PAGE electrophoresis utilized the Nupage PreCast gel system (Invitrogen) in accordance with the manufacturer's protocol. Protein samples (30 mg) were mixed with $2 \times$ sample buffer (100 mM Tris-HCl pH 6.5, $4 \%$ [w/v] SDS, $20 \%$ [v/v] glycerol $200 \mathrm{mM} \mathrm{DTT} \mathrm{and}$ $0.05 \%$ [w/v] bromphenol blue) and heated to $80^{\circ} \mathrm{C}$ for 10 min before being applied on 4 to $12 \%$ Bis-Tris gels run in $1 \times$ MES buffer (Invitrogen) at $200 \mathrm{~V} / 120 \mathrm{~mA}$ for $45 \mathrm{~min}$. Gels were stained with Simply Blue SafeStain (Invitrogen) according to the microwave protocol and imaged by a GEL DOC 2000 (Bio-Rad).

Monoclonal antibodies. Four different MAbs (5E10, 7G1, 4H4 and 1G11) developed against Aliivibrio salmonicida Strain LFI 83001 (Espelid 1986), with specificity to an uncharacterized $24 \mathrm{kDa}$ protein, were utilized. In the present study, the pooled MAbs, which were to be identified by mass spectrometry (MS), showed specificity towards a cell surface antigen with a molecular weight corresponding to $20 \mathrm{kDa}$.
Western blot analysis. Proteins separated by SDSPAGE were transferred to Hybond ECL nitrocellulose membrane (Amersham Biosciences) by semi-dry electrophoretic blotting with a 2117-250 Novablot electrophoretic transfer kit (LKB). Protein transfer was performed using the Towbin buffer system, with the transfer carried out at room temperature applying $20 \mathrm{~V}$ and $150 \mathrm{~mA}$ for $90 \mathrm{~min}$. Non-specific binding was blocked by incubating the membrane in blocking buffer of $5 \%(\mathrm{w} / \mathrm{v})$ skim milk (Nestle) in TBS-T (150 mM NaCl, 10 mM Tris-HCl, pH 8.0, 0.1\% Tween20 ), for $1 \mathrm{~h}$ with gentle agitation at $20^{\circ} \mathrm{C}$. MAbs diluted in TBS-T were added and incubated overnight at $4^{\circ} \mathrm{C}$ with gentle agitation. Horseradish peroxidase conjugated goat anti-mouse IgG (BD-Pharmingen) identified the positive antibody reactions developed using the luminol reagent solution (Santa Cruz Biotechnology) in combination with a Lumi-ImagerF1 (Mannheim Boehringer).

Protein spot preparation and collection of MS data. Excision, reduction and alkylation of protein spots and extraction of trypsin-generated peptides are identical to previous descriptions (Karlsen et al. 2008). Protein mass fingerprint (PMF) mass spectra were obtained on a MALDI micro MX (Waters Corporation). MS/MS data were obtained on a Q-TOF UltimaGlobalTM MS equipped with an electro-spray ion source interface online with a CapLC autosampler (nanoACQUITY Ultra Performance LC). Mass spectral data were recorded by means of automated data-dependent switching between MS and MS/MS mode based upon ion intensity, mass and charge state. Fragmentation spectra were collected from mass to charge ratios (m/z) 50 to 2000 and 800 to 3200 for MS/MS and PMF, respectively. PMF spectra were collected as a summation of up to 100 laser shots. Both MS instruments were operated in the positive ion mode under the MassLynx 4.1 software on a Windows XP workstation. For both MS analyses, peptides were concentrated and desalted on C-18 pipette tips (Varian). Peptide ionization for MALDI was achieved by mixing the peptide solution with 1,1cyano-4-hydroxy-trans-cinnamic acid $\left(10 \mathrm{mg} \mathrm{ml}^{-1}\right.$ in $0.1 \%$ trifluoroacetic acid: acetonitrile, 1:1, v/v) directly on the target. Electrospray ionization peptides were eluted in $0.1 \%$ formic acid. Instruments and software were from Waters Corporation.

Protein identification. MS data were searched against the NCBInr database and the recently sequenced and completed genome of Aliivibrio salmonicida (Hjerde et al. 2008) on an in-house Mascot server (Ver. 2.2; Matrix Science). We assume that peptide ions were monoisotopic (MALDI) or contained up to 3 charged residues (MS/MS), oxidized at methionine residues and carbamidomethylated at cysteine resi- 
dues with up to 1 missed trypsin cleavage. Mass accuracy of $100 \mathrm{ppm}$ was the window of error allowed for matching the peptide mass values, while tolerances were set to $100 \mathrm{ppm}$ and $1 \mathrm{Da}$ for the peptide precursors and the fragment ions, respectively. For unmatched peptides, however, good quality MS/MS spectra were subjected to automated de novo sequencing using the Peaks Studio software Ver. 3.0 (Bioinformatics Solutions) (Ma et al. 2003).

\section{RESULTS}

\section{Identification of an immunogenic $20 \mathrm{kDa} O M P$}

The OMP fraction of Aliivibrio salmonicida was utilized to determine the immunogenic protein recognized by the pooled MAbs. As revealed by Western blot, 1 single band reacted with the MAbs (Fig. 1, Lane III). To pinpoint the exact immunoreactive protein on the SDS-PAGE gel (Fig. 1, Lane II), 4 bands in the same molecular weight area were isolated from the gel and
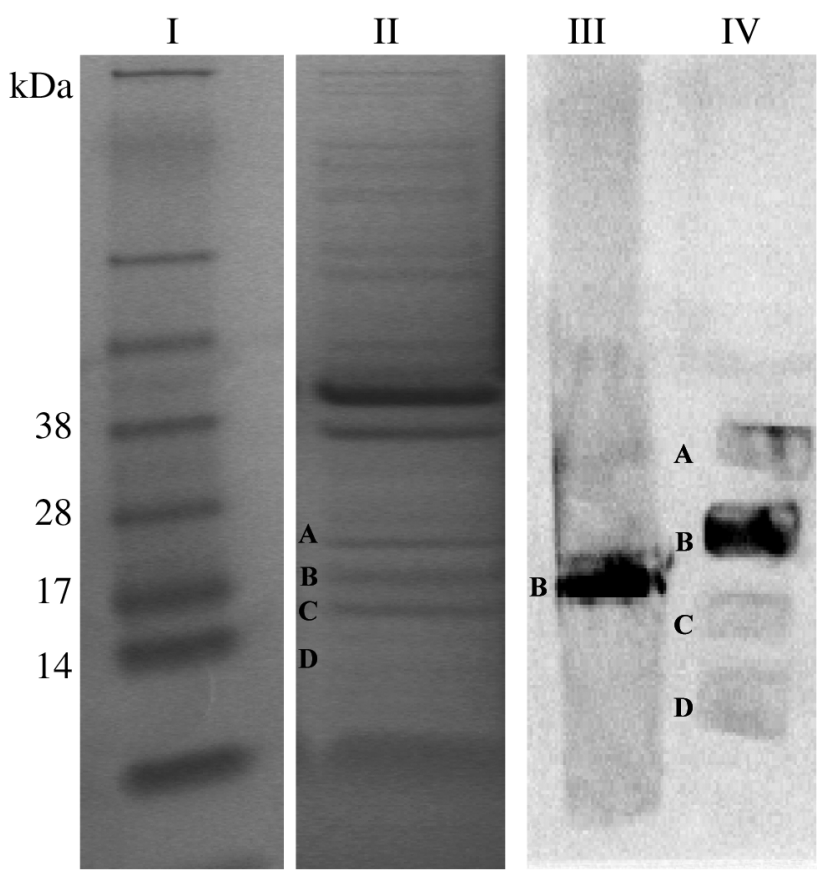

Fig. 1. Aliivibrio salmonicida. Sodium dodecyl sulfate polyacrylamide gel electrophoresis (SDS-PAGE) and Western blot of A. salmonicida outer membrane proteins. Lane II: SDSPAGE of membrane proteins. Lane III: Western blot of the protein band containing the immunoreactive protein, corresponding to Protein Band B in Lanes II and IV. Protein bands indicated by A, B, C and D in Lane II were all blotted individually to pinpoint the immunoreactive protein. Lane IV: Western blot of Protein Bands A, B, C and D from Lane II. Lane I represents the protein standard SeeBlue Plus2 Standard (Invitrogen) transferred separately before being blotted. The immunogenic protein band was allocated (Fig. 1, Lane IV), and analysis of the collected MS data identified the antigenic OMP as a Pal-like protein.

\section{2-D analysis of the outer membrane and secreted proteome}

OMPs and ECPs of Aliivibrio salmonicida resolved in the $\mathrm{pH}$ range of 3 to 11 and separated in a $12 \%$ SDSPAGE are presented in Fig. 2. The spots represent proteins expressed at low temperature at low osmotic pressure. The numbers of identified spots were quantified to 120 and 180 for the OMPs and ECPs, respectively. Spots marked by arrowheads (82) are identified protein entries, annotated in accordance with expected cell compartments or function (Table 1). Several of the identified proteins are also annotated as putative membrane or exported proteins in the genome of A. salmonicida (Hjerde et al. 2008). Some highly expressed proteins, such as chaperone DnaK and GroEL, are identified in both the outer membrane and extracellular fraction of $A$. salmonicida (Spot 234/142 and 233/143, respectively). The presence of the immunogenic Pal (Spot 227) was also confirmed in the OMP fraction by MS analysis and by Western blot of both fractions (Fig. 2). Membrane association of homologs to many of the predicted $A$. salmonicida OMPs and ECPs were confirmed by proteomic studies in other bacteria (Table 2). Nonetheless, several of the metabolic proteins like Eno, Fba, AccC/D are well characterized cytoplasmic proteins and are likely to represent cytoplasmic contaminants. Other metabolic proteins, such as GapA and GlyA, have been extracted from OMPs and ECPs in other bacteria (Ying et al. 2005, Voigt et al. 2006). Although they may be cytoplasmic contaminants, they cannot entirely be excluded as legitimate components of the A. salmonicida outer membrane.

\section{Cloning and sequence analysis}

To further verify the identity of the putative Pal protein, the corresponding gene was cloned into the Gateway pDEST17 vector and expressed in Escherichia coli of CodonPlus cells. Both the insoluble and soluble fractions of the resulting cell lysate contained the heterologously expressed Pal protein (Fig. 3). Pooled MAbs demonstrated specificity to both fractions and the Aliivibrio salmonicida OMP extract in a molecular weight area of $20 \mathrm{kDa}$. The estimated sizes correspond to the theoretical molecular weight of the A. salmonicida Pal protein, which is $19755 \mathrm{Da}$. Expression of the Pal pro- 

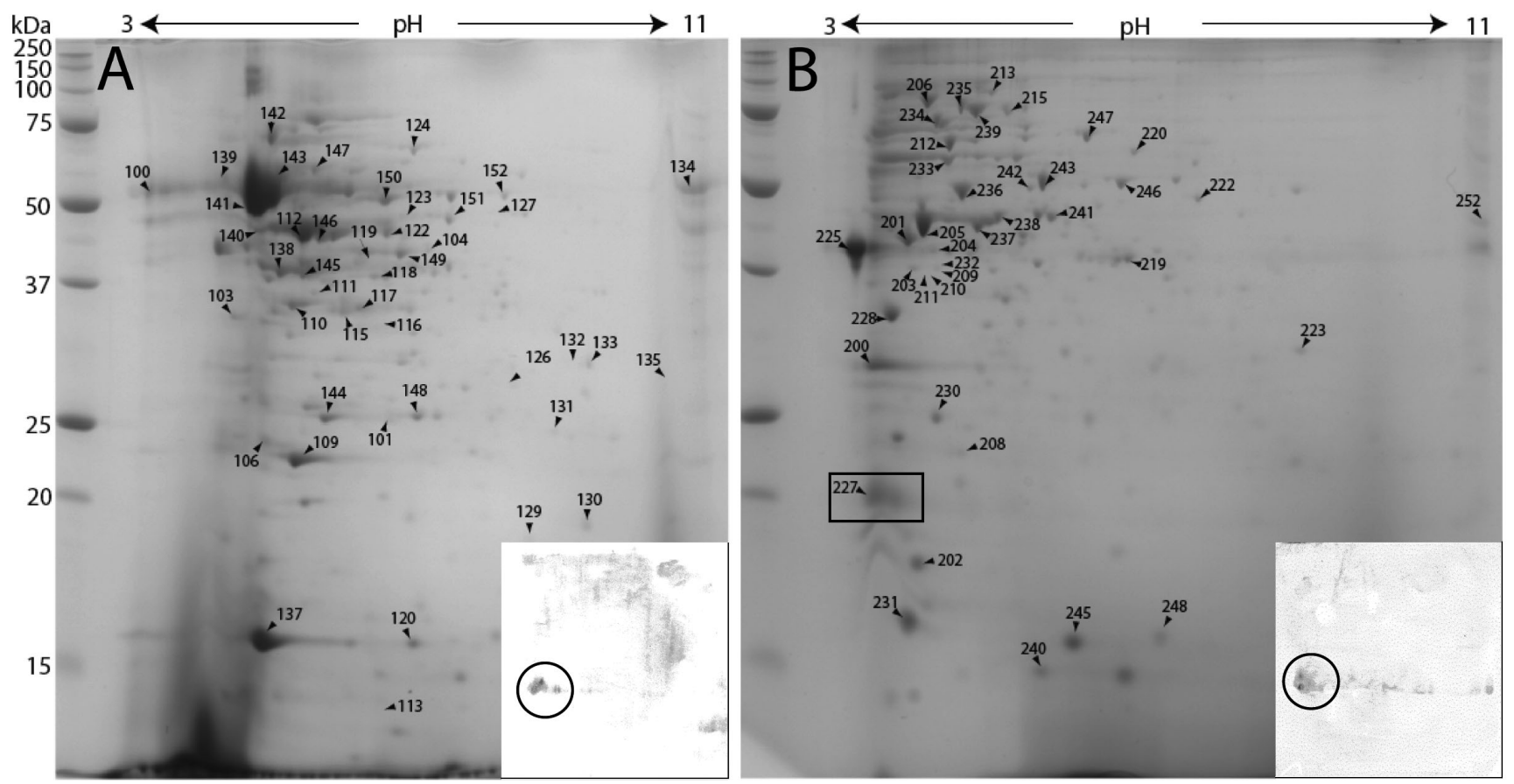

Fig. 2. Aliivibrio salmonicida Strain LFI315. Proteome reference map of (A) A. salmonicida extracellular products (ECPs) and (B) outer membrane proteins (OMPs). Proteins $(150 \mu \mathrm{g})$ isolated from mid-log phase cells were focused on $13 \mathrm{~cm} \mathrm{NL} \mathrm{pH} 3$ to $11 \mathrm{immo}$ bilized $\mathrm{pH}$ gradient strips and by $12 \%$ SDS-PAGE. Arrowheads represent spots with protein entries. See Table 1 for protein annotation. The marked rectangular area enclosing Spot 227 in the OMP reference map indicates the immunogenic Pal. The Pal protein was not present to a detectable level by Coomassie in the ECP fraction. Western blot of A. salmonicida ECPs (A, inset) and OMPs (B, inset) identified the immunoreactive protein (circled) in both fractions. The antigenic protein was recognized by use of peritoneal fluid (ascites) from immunized mice

Table 1. (Continued on next page) Aliivibrio salmonicida. Identification and predicted function of A. salmonicida outer membrane proteins (OMPs) and extracellular products (ECPs) grown. Cells grown at $7.5^{\circ} \mathrm{C}$ in Lubria-Bertina containing $1.0 \% \mathrm{NaCl}$, and harvested in mid-log phase $(\mathrm{OD}=0.65)$. Spot numbers match those marked in Fig. $2(\mathrm{ECPs}=100$ numbers, OMPs $=200$ numbers). Proteins/peptides with no identity score are not listed. Gi: GenInfo identifier

\begin{tabular}{|llc|}
\hline Protein Gi no. & Protein & Spot ID \\
\hline Cell motility and secretion & & 232 \\
209695754 & Flagellin subunit A, FlaA & 211 \\
209695749 & Flagellin subunit C, FlaC & $204 / 210 / 138$ \\
209695748 & Flagellin subunit D, FlaD & 203 \\
209695747 & Flagellin subunit E, FlaE & 124 \\
209695935 & Flagellin subunit F, FlaF & 109 \\
209695756 & Putative flagellar hook-associated protein, FlgK & 111 \\
Folding/repair/assembly & & 130 \\
209695865 & Putative peroxidase/antioxidant, AhpC \\
209808931 & Peptide methionine sulfoxide reductase \\
209693674 & Thiol:disulfide interchange protein, DsbA \\
209693911 & FKBP-type peptidyl-prolyl cis-trans isomerase, FkpA & 200 \\
209695843 & Outer membrane protein assembly factor, YaeT & 235 \\
209695891 & Chaperone, DnaK & $234 / 142$ \\
209693650 & Chaperone, GroEL & $233 / 143$ \\
Transport & & 148 \\
209695418 & Lysine-, arginine-, ornithine-binding protein, ArgT & 201 \\
209693642 & Putative cystine ATP-binding cassette transporter & $205 / 140$ \\
209695701 & Outer membrane fatty acid transport protein precursor, FadL & 212 \\
209696083 & Outer membrane channel protein, TolC \\
209696285 & Putative OMP-associated TonB-dependent receptor & 228 \\
209694180 & Major outer membrane protein, OmpU \\
209696443 & ATP synthase beta chain, AtpD & 236 \\
& & \\
& & \\
\end{tabular}


Table 1 (continued)

\begin{tabular}{|c|c|c|}
\hline Protein Gi no. & Protein & Spot ID \\
\hline 209808860 & Outer membrane efflux protein & 237 \\
\hline 209696445 & ATP synthase alpha subunit, AtpA & $242 / 243$ \\
\hline \multicolumn{3}{|c|}{ Outer membrane integrity } \\
\hline 209693974 & Organic solvent tolerance protein precursor, $\operatorname{Imp}$ & 206 \\
\hline 209694546 & Rare lipoprotein A & 219 \\
\hline 209695366 & Peptidoglycan-associated lipoprotein precusor, Pal & 227 \\
\hline 209694545 & Penicillin-binding protein 5 precursor, DacA & 255 \\
\hline \multicolumn{3}{|c|}{ Transcription/translation } \\
\hline 209694252 & Ribosome-associated inhibitor protein A, RaiA & 125 \\
\hline 209694218 & Elongation factor $\mathrm{G}$ & 239 \\
\hline 209696169 & 50s ribosomal subunit protein L9 & 240 \\
\hline 209695311 & Seryl-tRNA synthetase, SerS & 242 \\
\hline 209809781 & Helix-turn-helix-type transcriptional regulator, AsnC family & $248 / 106$ \\
\hline \multicolumn{3}{|c|}{ Extracellular proteins } \\
\hline 208009581 & Putative exported protein & 101 \\
\hline 208009252 & Putative exported protein & 104 \\
\hline 208010625 & Putative exported protein & 112 \\
\hline 209693976 & Exported protein & 131 \\
\hline 209695629 & Putative exported protein & 134 \\
\hline 209809063 & Putative exported protein & 146 \\
\hline \multicolumn{3}{|c|}{ Metabolism/biosynthesis } \\
\hline 209693789 & Polysaccharide biosynthesis protein & 104 \\
\hline 209694150 & Fructose-bisphosphate aldolase, Fba & 110 \\
\hline 209695316 & Glyceraldehyde-3-phosphate dehydrogenase, GapA & 115 \\
\hline 208007913 & Malate dehydrogenase, Mdh & 117 \\
\hline 209694652 & Iron-containing alcohol dehydrogenase & 118 \\
\hline 209695632 & Adenylosuccinate lyase, PurB & 123 \\
\hline 209694483 & Formyltetrahydrofolate deformylase, PurU & 126 \\
\hline 209808904 & Succinylarginine dihydrolase, AstB & 127 \\
\hline 209696337 & Glutamine synthetase, GlnA & 139 \\
\hline 209694149 & Phosphoglycerate kinase & 145 \\
\hline 209695306 & Alanine dehydrogenase, Ald & 149 \\
\hline 209809185 & Glycerol kinase, GlpK & 150 \\
\hline 209696119 & Dihydrolipoamide dehydrogenase & 150 \\
\hline 209693743 & Glutathione reductase & 151 \\
\hline 209694326 & Inosine-5'-monophosphate dehydrogenase, GuaB & 152 \\
\hline 209695933 & CTP synthase, PyrG & 220 \\
\hline 209696240 & Biotin carboxylase, AccC & 222 \\
\hline 209694635 & Acetyl-CoA carboxylase subunit beta, AccD & 223 \\
\hline 209695932 & Enolase, Eno & 238 \\
\hline 209694441 & Serine hydroxymethyltransferase, GlyA & $241 / 122$ \\
\hline 209696033 & Dihydrolipoamide dehydrogenase, LpdA & 246 \\
\hline 209694423 & Succinate dehydrogenase flavoprotein subunit, SdhA & 247 \\
\hline 209693783 & Putative pseudaminic acid biosynthesis protein & 254 \\
\hline Attachment and colonization & $\mathrm{N}$-acetylglucosamine-binding protein $\mathrm{A}, \mathrm{GbpA}$ & $100 / 141$ \\
\hline \multicolumn{3}{|c|}{ DNA transposition } \\
\hline 209809238 & Transposase & 129 \\
\hline \multicolumn{3}{|c|}{ Hypothetical proteins } \\
\hline 209693960 & Hypothetical protein & 133 \\
\hline 209694793 & Hypothetical protein & 135 \\
\hline 209809718 & Unidentified product & 137 \\
\hline \multicolumn{3}{|c|}{ Membrane proteins with unknown function } \\
\hline 209694987 & Outer membrane protein & $202 / 253$ \\
\hline 209694766 & Outer membrane protein & 213 \\
\hline 209694253 & Outer membrane protein & 230 \\
\hline 209694320 & Putative outer membrane protein & 208 \\
\hline 209694682 & Putative outer membrane protein & $225 / 252$ \\
\hline 209693880 & Putative outer membrane protein & 234 \\
\hline 209695331 & Putative outer membrane protein & 245 \\
\hline 209696425 & Putative outer membrane protein & 245 \\
\hline
\end{tabular}


Table 2. Aliivibrio salmonicida. Identified homologs of membrane-associated protein confirmed by proteomic studies in other bacteria. Cells grown at $7.5^{\circ} \mathrm{C}$ in Lubria-Bertina containing $1.0 \% \mathrm{NaCl}$, and harvested in mid-log phase (OD = 0.65). Gi: GenInfo identifier. Spot numbers match those marked in Fig. 2 (ECPs $=100$ numbers, OMPs $=200$ numbers)

\begin{tabular}{|c|c|c|c|c|}
\hline Protein Gi no. & Protein & Species & Function & Spot ID \\
\hline 81728747 & General secretion pathway protein E & Vibrio parahaemolyticus & Component of T2SS & 101 \\
\hline 78033454 & Hypothetical protein & $\begin{array}{l}\text { Magnetospirillum } \\
\text { gryphis-waldense }\end{array}$ & Unknown & 113 \\
\hline 58254493 & DNA alkylation repair enzyme & Lactobacillus acidophilus & DNA repair & 120 \\
\hline 262192021 & ISSod13 transposase & Vibrio cholerae & Genetic rearrangement & 132 \\
\hline 59713085 & $\begin{array}{l}\text { Phosphoenolpyruvate carboxykinase, } \\
\text { PckA }\end{array}$ & Aliivibrio fischeri & $\begin{array}{l}\text { Energy metabolism } \\
\text { carbohydrates }\end{array}$ & 147 \\
\hline 61212678 & Exodeoxyribonuclease 7 large subunit & Vibrio vulnificus & DNA excision & 151 \\
\hline 22653130 & Outer membrane protein, PorB & Neisseria meningitidis & Membrane transport & 231 \\
\hline 28897600 & Asparagine synthetase B, AsnB & Vibrio parahaemolyticus & Metabolism & 252 \\
\hline 83716747 & Flagellum-specific ATP synthase, FliI & Burkholderia thailandensis & Cell motility and secretion & 252 \\
\hline
\end{tabular}

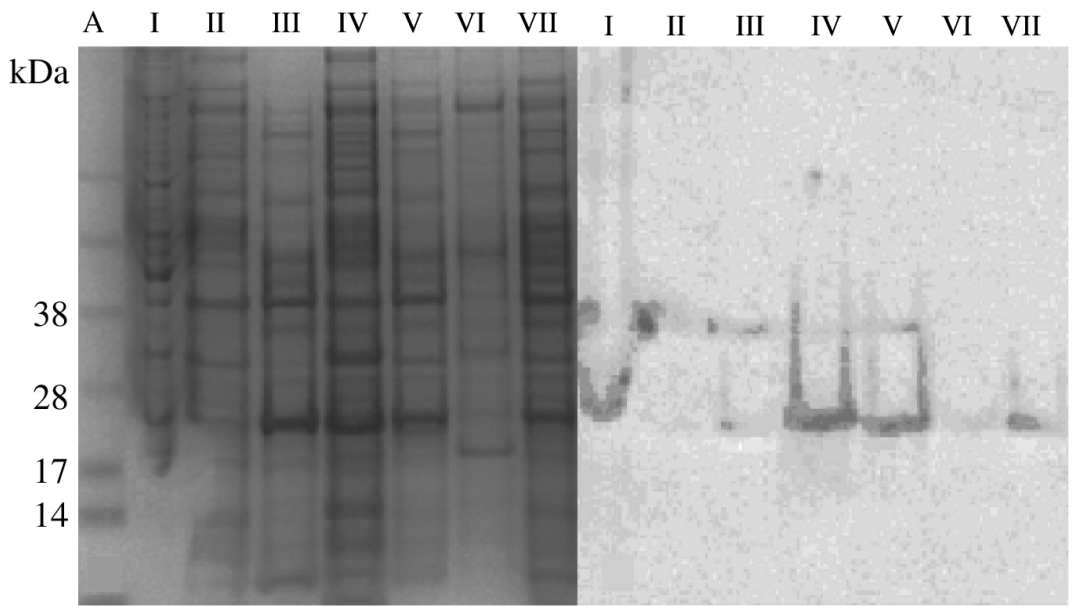

Fig. 3. Aliivibrio salmonicida. SDS-PAGE and Western blot of A. salmonicida outer membrane proteins (OMPs) and the heterologously expressed Pal protein. Lane I: A. salmonicida OMP extract. Lanes II/III: negative controls; insoluble and soluble cell fractions of BL21 CodonPlus (DE3) expressing an irrelevant protein (VP4 from infectious pancreatic necrosis virus). Lanes IV/V: insoluble and soluble cell fractions of Escherichia coli Strain BL21 CodonPlus (DE3) expressing the A. salmonicida Pal protein. Lanes VI/VII: insoluble and soluble cell fractions of E. coli Strain BL21 (DE3) expressing the Pal protein. Lane A: SeeBlue Plus2 Standard (Invitrogen)

tein or the folding to its native state appeared to be temperature dependent, as the detection level on the immunoblot was best retained when expressed at $20^{\circ} \mathrm{C}$ compared to $30^{\circ} \mathrm{C}$ (data not shown). The transformed E. coli Strain BL21 (DE3) did not express the recombinant protein to any detectable level.

\section{DISCUSSION}

Aliivibrio salmonicida is the aetiological agent of cold water vibriosis in farmed fish species, a disease that today is fully controlled by vaccination. The molecular mechanisms behind the protective nature of the vaccine are unknown, and no specific antigen has been found. It is therefore in our interest to search for immunogenic OMPs that induce responses in fish, as well as in mouse and rabbit (Espelid et al. 1987). In the present study we found a Pal that was present in both the OMP extract as well as in the ECPs from A. salmonicida grown in LB medium. The mature expressed protein has an apparent molecular mass of $20 \mathrm{kDa}$, similar to the theoretical molecular weight of $19755 \mathrm{Da}$, predicted from the 185 amino acid sequence. Also, the first 28 amino acids on the Nterminal part of the Pal protein sequence are predicted to constitute a hydrophobic lipoprotein signal sequence of 2873 Da. Tol-Pal systems appear ubiquitous in Gram-negative bacteria, and the gene cluster present in $A$. salmonicida is identical to, for example, Escherichia coli and Vibrio cholerae (ybgC-tolQ-tolR-tolA-tolB-pal-ybgF). No designed experiment has demonstrated that the protein is in fact peptidoglycan-associated in A. salmonicida. However, its highly conserved homology to other Pals within the Vibrionaceae and in E. coli and its location in the outer membrane suggest that the protein belongs to the Pal family. Pal proteins are shed from the bacterial surface into the circulation of animals and induce a strong antibody response in many different species (Liang et al. 2005, Godlewska et al. 2009). Although the Pal protein is highly immunogenic in Atlantic salmon, it is assumed that VS-P1 has a stronger effect in mediating the humoral immune response. This assumption is based on the fact that $>90 \%$ of the antigen response in the serum of Atlantic 
salmon immunized with $A$. salmonicida is targeting the VS-P1 complex (Espelid et al. 1987). Additional experiments are required to elucidate whether A. salmonicida Pal plays a role in the pathogenesis of cold water vibriosis.

The heterologously expressed Aliivibrio salmonicida Pal-like product was found to be immunogenic by Western blot analysis, which further supports the correct annotation and antigenic nature of the protein. The immunogenic property of the recombinantly expressed protein excludes any possible cross immunogenicity

owing to A. salmonicida LPS, as in the VS-P1 complex.

Little is known about the constituents of the Aliivibrio salmonicida surface layer that circulates in sepsis. The LPS layer or OMP/LPS complexes such as VS-P1 were suggested to act as the immunodominant antigens that triggered the immune responses in Atlantic salmon. However, immunization of Atlantic salmon with LPS provided little protection, whereas an improved immunity was observed with the VS-P1 complex. Still, whole inactivated bacterial cells improve the efficacy (Bøgwald et al. 1992), which suggests that antigens other than LPS or the OMP/LPS complex are involved in the stimulation of the fish immune response, such as the Pal protein. The LPS of Gramnegative bacteria may, in sepsis, act as toxins that elicit inflammation activity. Recent studies indicate that lipoproteins and outer surface proteins can also modulate the host immune response, as the lipoproteins are recognized by Class II Toll-like receptors (TLR2) of antigen presenting cells (Aliprantis et al. 1999). Some lipoproteins, such as Pal, can also be secreted into the bloodstream during infection and contribute to the development of septic shock (Hellman et al. 2002, Liang et al. 2005). Although the role of Pal in pathogenesis is not clearly defined, mutations in the pal gene result in decreased virulence (Godlewska et al. 2009).

The fact that we have cloned and expressed the immunogene VSAL_I1899 from Aliivibrio salmonicida LFI1238 makes it possible to test the protective properties of the protein. Whether it can be regarded as a suitable candidate in developing a subunit vaccine for cold water vibriosis in Atlantic salmon remains to be elucidated. The application of Pal in immunoprophylaxis is supported by the fact that all Pal proteins studied so far are highly immunogenic. By construction of a gene-specific knockout the importance of the Pal protein in cold water vibriosis can be tested in an infection model.

Acknowledgements. This work was funded by the University of Tromsø, Norway, and the National Program for Research and Functional Genomics in Norway (FUGE).

\section{LITERATURE CITED}

Aliprantis AO, Yang RB, Mark MR, Suggett S and others (1999) Cell activation and apoptosis by bacterial lipoproteins through Toll-like receptor-2. Science 285:736-739

Bøgwald J, Stensvåg K, Hoffman J, Espelid S, Jørgensen T (1990) Electrophoretic and immunochemical analysis of surface antigens of the fish pathogens Vibrio anguillarum and Vibrio salmonicida. J Fish Dis 13:293-301

Bøgwald J, Stensvåg K, Hoffman J, Jørgensen T (1991) Antibody specificities in Atlantic salmon, Salmo salar L., against the fish pathogens Vibrio salmonicida and Vibrio anguillarum. J Fish Dis 14:79-87

> Bøgwald J, Stensvg K, Hoffman J, Holm KO, Jørgensen TØ (1992) Vaccination of Atlantic salmon, Salmo salar L., with particulate lipopolysaccharide antigens from Vibrio salmonicida and Vibrio anguillarum. Fish Shellfish Immunol 2:251-261

Bornø G, Sviland C, Jensen BB, Tarpai A and others (2010) Helsesituasjonen hos laksefisk 2009. National Veterinary Institute, Oslo

Bradford MM (1976) A rapid and sensitive method for the quantitation of microgram quantities of protein utilizing the principle of protein-dye binding. Anal Biochem 72: $248-254$

Colquhoun DJ, Sørum H (2001) Temperature dependent siderophore production in Vibrio salmonicida. Microb Pathog 31:213-219

Colquhoun DJ, Alvheim K, Dommarsnes K, Syvertsen C, Sørum H (2002) Relevance of incubation temperature for Vibrio salmonicida vaccine production. J Appl Microbiol 92:1087-1096

Edebrink P, Jansson PE, Bogwald J, Hoffman J (1996) Structural studies of the Vibrio salmonicida lipopolysaccharide. Carbohydr Res 287:225-245

Egidius E, Andersen K, Clausen E, Raa J (1981) Coldwater vibriosis or 'Hitra disease' in Norwegian salmonid farming. J Fish Dis 4:353-354

> Egidius E, Wiik R, Andersen K, Hoff KA, Hjeltnes B (1986) Vibrio salmonicida sp. nov., a new fish pathogen. Int J Syst Bacteriol 36:518-520

Espelid S (1986) Fremstilling av monoklonale antistoff mot Vibrio-bakterier fra 'Hitra-sjuk' laks (Salmo salar). MS thesis, University of Tromsø

Espelid S, Hjelmeland K, Jørgensen T (1987) The specificity of Atlantic salmon antibodies made against the fish pathogen Vibrio salmonicida, establishing the surface protein VS-P1 as the dominating antigen. Dev Comp Immunol 11:529-537

Espelid S, Holm KO, Hjelmeland K, Jørgensen T (1988) Monoclonal antibodies against Vibrio salmonicida: the causative agent of cold water vibriosis (Hitra disease) in Atlantic salmon, Salmo salar L. J Fish Dis 11:207-214

Fidopiastis PM, Sørum H, Ruby EG (1999) Cryptic luminescence in the cold-water fish pathogen Vibrio salmonicida. Arch Microbiol 171:205-209

- Godlewska R, Wisniewska K, Pietras Z, Jagusztyn-Krynicka EK (2009) Peptidoglycan-associated lipoprotein (Pal) of Gram-negative bacteria: function, structure, role in pathogenesis and potential application in immunoprophylaxis. FEMS Microbiol Lett 298:1-11

> Graf J, Dunlap PV, Ruby EG (1994) Effect of transposoninduced motility mutations on colonization of the host light organ by Vibrio fischeri. J Bacteriol 176:6986-6991

Hellman J, Roberts JDJ, Tehan MM, Allaire JE, Warren HS (2002) Bacterial peptidoglycan-associated lipoprotein is released into the bloodstream in Gram-negative sepsis 
and causes inflammation and death in mice. J Biol Chem 277:14274-14280

Hjelmeland K, Stensvag K, Jørgensen T, Espelid S (1988) Isolation and characterization of a surface layer antigen from Vibrio salmonicida. J Fish Dis 11:197-205

Hjerde E, Lorentzen MS, Holden MT, Seeger K and others (2008) The genome sequence of the fish pathogen Aliivibrio salmonicida strain LFI1238 shows extensive evidence of gene decay. BMC Genomics 9:616-630

Jørgensen T, Midling K, Espelid S, Nilsen R, Stensvåg K (1989) Vibrio salmonicida, a pathogen in salmonids, also causes mortality in net-pen captured cod (Gadus morhua). Bull Eur Assoc Fish Pathol 9:42-44

Karlsen C, Paulsen SM, Tunsjø HS, Krinner S, Sørum H, Haugen P, Willassen NP (2008) Motility and flagellin gene expression in the fish pathogen Vibrio salmonicida: effects of salinity and temperature. Microb Pathog 45:258-264

Knudsen G (1991) Karakterisering av vekstkrav og analyse av et kryptisk plasmid ( $\mathrm{pVS} 1$ ) hos Vibrio salmonicida. MS thesis, University of Tromsø

Laemmli UK (1970) Cleavage of structural proteins during the assembly of the head of bacteriophage T4. Nature 227: 680-685

Lee JH, Rho JB, Park KJ, Kim CB and others (2004) Role of flagellum and motility in pathogenesis of Vibrio vulnificus. Infect Immun 72:4905-4910

Liang MD, Bagchi A, Warren HS, Tehan MM, and others (2005) Bacterial peptidoglycan-associated lipoprotein: a naturally occurring toll-like receptor 2 agonist that is shed into serum and has synergy with lipopolysaccharide. J Infect Dis 191:939-948

Ma B, Zhang K, Hendrie C, Liang C, Li M, Doherty-Kirby A, Lajoie G (2003) PEAKS: powerful software for peptide de novo sequencing by tandem mass spectrometry. Rapid Comm Mass Spectrom 17:2337-2342

McKevitt M, Brinkman MB, McLoughlin M, Perez C and oth-

Editorial responsibility: David Bruno,

Aberdeen, UK ers (2005) Genome scale identification of Treponema pallidum antigens. Infect Immun 73:4445-4450

Ormonde P, Horstedt P, O'Toole R, Milton DL (2000) Role of motility in adherence to and invasion of a fish cell line by Vibrio anguillarum. J Bacteriol 182:2326-2328

Parsons LM, Lin F, Orban J (2006) Peptidoglycan recognition by $\mathrm{Pal}$, an outer membrane lipoprotein. Biochemistry 45:2122-2128

> Richardson K (1991) Roles of motility and flagellar structure in pathogenicity of Vibrio cholerae: analysis of motility mutants in three animal models. Infect Immun 59:2727-2736

Stork M, Di Lorenzo M, Mourino S, Osorio CR, Lemos ML, Crosa JH (2004) Two tonB systems function in iron transport in Vibrio anguillarum, but only one is essential for virulence. Infect Immun 72:7326-7329

Stuge T (1992) Degradering av bakterieantigener (Vibrio salmonicida) i gastrointestinale safter fra Atlantisk laks (Salmo salar L.). MS thesis, University of Tromsø

Urbanczyk H, Ast JC, Higgins MJ, Carson J, Dunlap PV (2007) Reclassification of Vibrio fischeri, Vibrio logei, Vibrio salmonicida and Vibrio wodanis as Aliivibrio fischeri gen. nov., comb. nov., Aliivibrio logei comb. nov., Aliivibrio salmonicida comb. nov. and Aliivibrio wodanis comb. nov. Int J Syst Evol Microbiol 57:2823-2829

> Uttakleic Raeder IL, Paulsen SM, Smalås AO, Willassen NP (2007) Effect of fish skin mucus on the soluble proteome of Vibrio salmonicida analysed by 2-D gel electrophoresis and tandem mass spectrometry. Microb Pathog 42:36-45

> Voigt B, Schweder T, Sibbald MJ, Albrecht D and others (2006) The extracellular proteome of Bacillus licheniformis grown in different media and under different nutrient starvation conditions. Proteomics 6:268-281

Ying T, Wang H, Li M, Wang J and others (2005) Immunoproteomics of outer membrane proteins and extracellular proteins of Shigella flexneri 2a 2457T. Proteomics 5: $4777-4793$

Submitted: June 1, 2010; Accepted: October 14, 2010 Proofs received from author(s): February 14, 2011 